\title{
Meta-analysis in effects of barefoot and athletic footwear on lower extremity stiffness during dynamic activity.
}

\author{
Jing LI ${ }^{1 \#}$, Hai-Bin Y ${ }^{2,3 * \#}$, Yung-Shen TSAI ${ }^{4 *}$ \\ ${ }^{1}$ College of Textiles and Apparel, Quanzhou Normal University, Quanzhou, PR China \\ ${ }^{2}$ School of Physical Education, Quanzhou Normal University, Quanzhou, PR China \\ ${ }^{3}$ Department of Sports Sciences, University of Taipei, Taiwan \\ ${ }^{4}$ Graduate Institute of Sports Equipment Technology, University of Taipei, Taiwan \\ \#These authors contributed equally to this work
}

\begin{abstract}
Objective:To search the original research and investigate the evidence relating to the effectiveness of the type of athletic footwear affects the regulation of lower extremity stiffness.

Method:Meta-analysis.

Results: There are 12 trails leg stiffness (Risk ratio RR-0.47, 95\% confidence interval CI: $\mathbf{- 0 . 7 0}$ to $\mathbf{- 0 . 2 5}$, the overall effect size $Z=4.13, p<0.001$ ), 10 trails knee stiffness (RR $-0.59,95 \%$ CI: $-\mathbf{0 . 8 2}$ to $-\mathbf{0 . 3 5}, Z=4.97$, $\mathrm{p}<0.001$ ) and 3 trails vertical stiffness (RR $-0.51,95 \%$ CI:-0.93 to $-0.10, Z=2.41, p=0.02$ ), meta-analysis found that athletic footwear were effective. But 10 trails ankle stiffness (RR 0.82, 95\% CI: 0.63 to 1.00, $\mathrm{Z}=8.74, \mathrm{p}<0.001$ ), and 4 trails hip stiffness (RR $0.46,95 \% \mathrm{CI}$ : 0.10 to $0.81, \mathrm{Z}=\mathbf{2 . 5 4}, \mathrm{p}=\mathbf{0 . 0 1}$ ) were opposite.

Conclusion: This review adds to the body of knowledge by strongly highlighting the dearth of literature exploring the effects of athletic footwear on lower extremity stiffness during dynamic activities. When shod leg, vertical and knee stiffness are decrease, but ankle and hip stiffness were increase compare to barefoot.
\end{abstract}

Keywords: Lower extremity stiffness, Athletic footwear, Barefoot, Meta-analysis.

Accepted on October 4, 2018

\section{Introduction}

Athletic footwear is necessary in the most sports activity, as provision of traction between the foot and the ground, control of motion, protection of the plantar surface of the foot, and attenuation of impact forces during activity [1,2]. Research has also shown how certain footwear can directly influence function. A common feature of modern athletic footwear is that of increased sole hardness or thickness which are marketed as providing cushioning against harmful impacts [3].

However, as footwear is introduced as a variable into the lower extremity-surface system, the series of springs that represent the lower extremity should adjust for the new substance in order to maintain total system stiffness [4] $1 / \mathrm{K}_{\text {total }}=1 / \mathrm{K}_{\text {leg }}+1 /$ $\mathrm{K}_{\text {surface }}+1 / \mathrm{K}_{\text {shoe. }}$. The "stiffness" concept has its origin in sports, as part of Hooke's law [5-9]. Research into stiffness in the human body is an escalating rate, possibly because stiffness has been associated with sporting performance and some lower extremity injuries. A large number of studies have compared walking and running kinetics, kinematics and electromyogram between barefoot and shod conditions [10-17]. Although reviews examining differences between barefoot and shod walking and running exist, the majority of these are narrative. Thus, some reviews do not describe clear methodology for literature searching nor systematically evaluate the quality of studies included, leaving them vulnerable to bias $[18,19]$. Where two systematic review of barefoot and shod biomechanics has been carried out, the focus was purely on kinematic, kinetic and muscle activity different and considered walking and running [20,21]. If the cushioning in athletic footwear attenuates impact, then overall lower extremity stiffness may be modified during dynamic activity. To date, some studies have examined the effects of athletic footwear on lower extremity stiffness performance during dynamic activities [22-25].

A key consideration, however, is whether athletic footwear effects lower extremity stiffness performance specifically. If so, what type of athletic footwear is better suited for increased stiffness performance? Consequently, the purpose of this systematic review was to search the body of scientific literature for original research, addressing the effects of athletic footwear 
on lower extremity stiffness during dynamic activities. To determine if the type of athletic footwear affects the regulation of lower extremity stiffness.

\section{Methods}

\section{Experimental approach to the problem}

This meta-analysis is reported in accordance with the preferred reporting items for meta-analyses (PRISMA) guidelines [18]. Several electronic databases were searched from the earliest available date up to the first week of February 2018, including Medline, Science Direct, Sports Discus, EMBASE, Web of Science, the Wiley Online Library, and Cochrane library, Journal of Gait and Posture, and the Journal of Biomechanics.

\section{Study criteria}

Studies were eligible if they met the following inclusion criteria: their sample was from an adult population with no musculoskeletal injuries. The primary objective of the original research paper was to determine the effect of different types of athletic footwear or different contact surface on lower extremity stiffness.

\section{Quality assessment}

Original research was reviewed using the physiotherapy evidence database (PEDro) scale [18]. Each study was scored according to the scale with each item graded as yes (1 point), no ( 0 points), or unable to determine ( 0 points) to give a total score out of 11 . Finally systematic review 12 studies,and 6 studies met the inclusion criteria [22,25-29].

\section{Data extraction}

Data from each trial were extracted from the available text. Meta-analysis was calculated using the Cochrane Collaboration Review Manager V.5.3 software (Cochrane Collaboration Review Manager).

\section{Results}

In total, we retrieved 1636 studies and included 12 studies in the systematic review. All of the studies were published or written after 2000 year. Of the 12 studies, we included 6 studies into meta-analyses based on the same outcome measures in each domain (Figure 1). Twenty-one types of intervention shoes were used in the included studies. The test protocol running speed from $2.2 \mathrm{~m} / \mathrm{s}$ to $5.5 \mathrm{~m} / \mathrm{s}$. Three kinds of dancer's jump landings. $2.2 \mathrm{~Hz}$ rope jumping. Three kinds of vertical jump and landing. Three kinds of basketball jump and landing.

The data from the twelve trials evaluating shoe-barefoot leg stiffness were pooled, all trials yielding results favouring the use of shoes for the effect of leg stiffness compared with a control. The pooled data indicated that shoes are effective for the effect of leg stiffness (RR-0.47, 95\% CI: -0.70 to $-0.25, \mathrm{Z}=$
4.13, $\mathrm{p}<0.001)$, with heterogeneity of results between trials being low $\left(\mathrm{I}^{2}=25 \%\right)$ (Figure 2a).

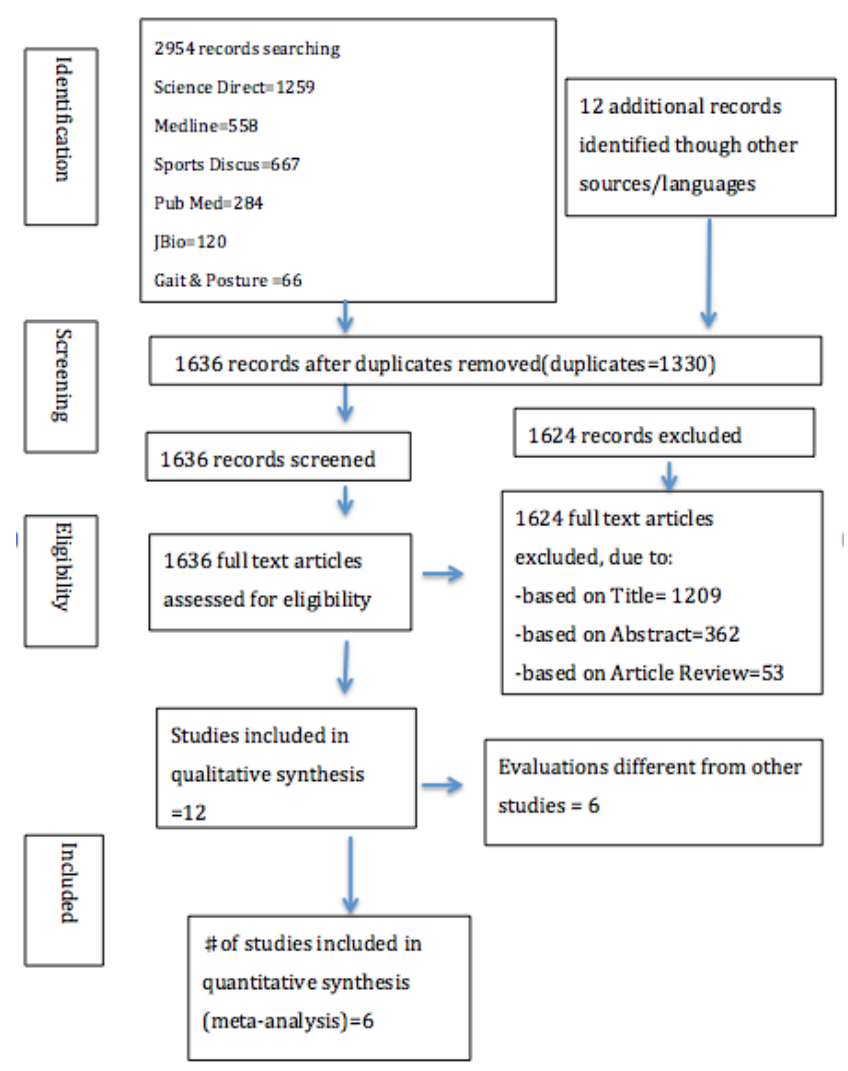

Figure 1. Criteria for selection of articles for review.

The data from the ten trials evaluating shoe-barefoot knee stiffness were pooled, all trials yielding results favouring the use of shoes for the effect of leg stiffness compared with a control. The pooled data indicated that shoes are effective for the effect of knee stiffness (RR $-0.59,95 \%$ CI: -0.82 to -0.35 , $\mathrm{Z}=4.97, \mathrm{p}<0.001)$, with heterogeneity of results between trials being low $\left(\mathrm{I}^{2}=20 \%\right)$ (Figure $\left.2 \mathrm{~b}\right)$.

The data from the ten trials evaluating shoe-barefoot ankle stiffness were pooled, with three yielding results favouring the use of shoes for the effect of ankle stiffness compared with a control. Seven trials don't favour the experimental intervention. The pooled data indicated that shoes are not effective for the effect of ankle stiffness (RR 0.82, 95\% CI: 0.63 to 1.00 , $\mathrm{Z}=8.74, \mathrm{p}<0.001$ ), with heterogeneity of results between trials being high $\left(\mathrm{I}^{2}=90 \%\right)$ (Figure $\left.2 \mathrm{c}\right)$.

The data from the four trials evaluating shoe-barefoot hip stiffness were pooled, all trials yielding results favouring the use of shoes for the effect of hip stiffness compared with a control. The pooled data indicated that shoes are not effective for the effect of hip stiffness (RR $0.46,95 \%$ CI: 0.10 to 0.81 , $\mathrm{Z}=2.54, \mathrm{p}=0.01$ ), with heterogeneity of results between trials being low $\left(\mathrm{I}^{2}=0 \%\right)$ (Figure $\left.2 \mathrm{~d}\right)$.

The data from the three trials evaluating shoe-barefoot vertical stiffness were pooled, all trials yielding results favouring the use of shoes for the effect of leg stiffness compared with a control. The pooled data indicated that shoes are effective for 
the effect of vertical stiffness (RR-0.51, 95\% CI: -0.93 to -0.10 , $\mathrm{Z}=2.41, \mathrm{p}=0.02)$, with heterogeneity of results between trials being low $\left(\mathrm{I}^{2}=0 \%\right)$ (Figure $\left.2 \mathrm{e}\right)$.

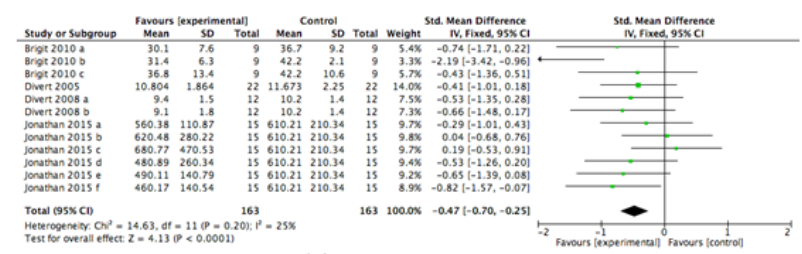

(a)

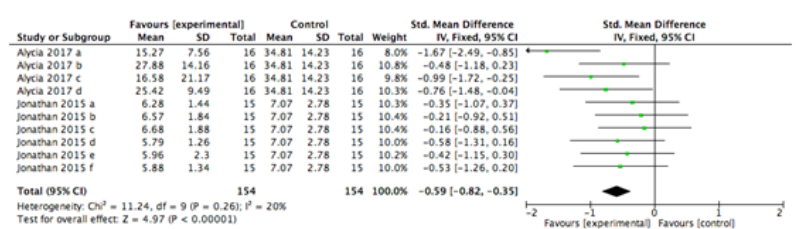

(b)

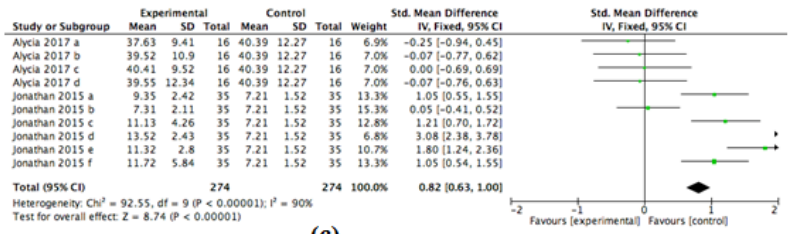

(c)

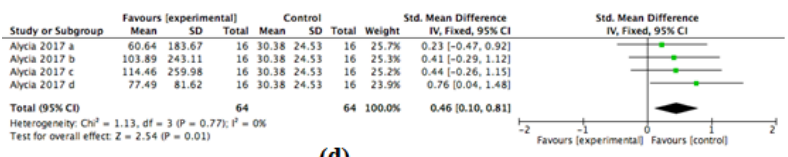

(d)

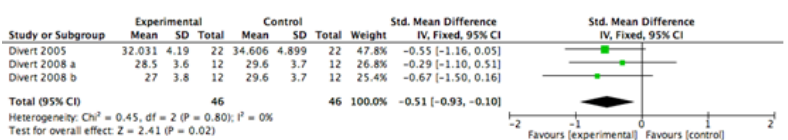

(e)

Figure 2. The forest plot of synthetic data for the shoe-barefoot lower extremity stiffness. The green squares indicate the effect size of every trail. The transverse lines show the $95 \%$ CI. Black diamond represents the pooled estimate the total effect. CI: Confidence Interval; SD: Standardized Errors.

\section{Discussion}

This review is unique because of its narrow focus on athletic footwear on lower extremity stiffness. Meta-analysis indicated that athletic footwear is effective for the effect on lower extremity stiffness during dynamic activities.

The results of our study (standardized mean difference, SMD range-0.59-0.82) indicated that the athletic footwear showed positive effects on low extremity stiffness during dynamic activities. We demonstrated that varied athletic footwear favors cushion performance. Moreover, compare to normal footwear with hard midsole hardness, soft midsole hardness (such as Asker C-38, C-40, C-45, C-50) [22,30] more positive for knee and ankle stiffness. Despite the volume of athletic footwear available, few have focused specifically on lower extremity stiffness during dynamic activities. One limitation of this review was the small number of studies that met the inclusion criteria, but this further emphasizes that athleticers are using various type of shoes with unpublished empirical evidence to substantiate the type, materials, and property of these athletic footwear.

This review adds to the body of knowledge by strongly highlighting the dearth of literature exploring that leg and vertical stiffness are decrease when shod compare to barefoot. The max force increased when barefoot $[27,28]$, according the equation: $\mathrm{K}_{\text {leg }}=\mathrm{F}_{\text {max }} / \Delta \mathrm{L} ; \mathrm{K}_{\mathrm{vert}}=\mathrm{F}_{\text {max }} / \Delta \mathrm{y}$, so there is no doubt that leg and vertical stiffness are decrease [8]. The result is similar as Jonathan et al. compare with barefoot wearing conventional and structured minimalist footwear run at the speed of $4.01 \mathrm{~m} / \mathrm{s}$, significantly decrease leg and vertical stiffness. Brigit et al. also confirmed that compare with barefoot wearing Adidas running shoe run at the speed of 3.5 $\mathrm{m} / \mathrm{s}$, significantly decrease leg stiffness. Similar result as Divert et al. compare with barefoot wearing running shoe and more light footwear run at the speed of $3.61 \mathrm{~m} / \mathrm{s}$, significantly decrease leg and vertical stiffness.

The result knee stiffness is decrease, but ankle and hip stiffness are increase when shod compare to barefoot [17]. Because change in the knee joint increase, but the angle change in ankle joint decrease [14,17], so according the equation [8], $\mathrm{K}$ stiffness $=\mathrm{M}$ joint moment $/ \Delta \Theta$ joint angle. Hip Extensor and flexor moment sig. reduced when barefoot. The result is similar as Jonathan et al. compare with barefoot wearing conventional and structured minimalist footwear run at the speed of $4.01 \mathrm{~m} / \mathrm{s}$, significantly increase ankle joint stiffness.

\section{Conclusion}

This review adds to the body of knowledge by strongly highlighting the dearth of literature exploring the effects of athletic footwear on lower extremity stiffness during dynamic activities. When shod leg, vertical and knee stiffness are decrease, but ankle and hip stiffness were increase compare to barefoot.

\section{Acknowledgement}

The authors are grateful for the financial support by the National Natural Science Foundation of Fujian (Project No. 2016J01680) and Quanzhou (No. 2016G058) and partially supported by the grant from the University of Taipei.

\section{References}

1. Yu HB, Monchai C, Tsai YS. Effects of athletic footwear on plantar force during rope skipping. Int J Exp Comput Biomech 2018; 4: 184-195.

2. Mcpoil TG. Athletic footwear: design, performance and selection issues. J Sci Med Sport 2000; 3: 260-267.

3. Baltich J, Maurer C, Nigg BM. Increased vertical impact forces and altered running mechanics with softer midsole shoes. PLoS One 2015; 10: e0125196.

4. Geick K, Geick R. Engineering Formulas (7th Edn.). New York, NY: McGraw Hill; 1997; 6. 
5. Spurrs RW, Murphy AJ, Watsford ML. The effect of plyometric training on distance running performance. Eur J Appl Physiol 2003; 89: 1-7.

6. Hobara H, Kimura K, Omuro K, Gomi K, Muraoka T, Iso $\mathrm{S}$, Kanosue K. Determinants of difference in leg stiffness between endurance- and power-trained athletes. J Biomech 2008; 41: 506-514.

7. Hobara H, Inoue K, Muraoka T, Omuro K, Sakamoto M, Kanosue K. Leg stiffness adjustment for a range of hopping frequencies in humans. J Biomech 2010; 43: 506-511.

8. Serpell BG, Ball NB, Scarvell JM, Smith PN. A review of models of vertical, leg, and knee stiffness in adults for running, jumping or hopping tasks. J Sports Sci 2012; 30: 1347-1363

9. Spurrs RW, Murphy AJ, Watsford ML. The effect of plyometric training on distance running performance. Eur J Appl Physiol 2003; 89: 1-7.

10. Bonacci J, Saunders PU, Hicks A, Rantalainen T, Vicenzino BG, Spratford W. Running in a minimalist and lightweight shoe is not the same as running barefoot: a biomechanical study. Br J Sports Med 2013; 47: 387-392.

11. Kerrigan DC, Franz JR, Keenan GS. The effect of running shoes on lower extremity joint torques. PM R J Inj Funct Rehab 2009; 1: 1058.

12. Kurz MJ, Stergiou N. Does footwear affect ankle coordination strategies? J Am Podiatr Med Assoc 2004; 94: 53-58.

13. Lieberman DE, Venkadesan M, Werbel WA, Daoud AI, DAndrea S, Davis IS, Mangeni RO, Pitsiladis Y. Foot strike patterns and collision forces in habitually barefoot versus shod runners. Nature 2010; 463: 531-535.

14. Morio C, Lake MJ, Gueguen N, Rao G, Baly L. The influence of footwear on foot motion during walking and running. J Biomech 2009; 42: 2081-2088.

15. Morley JB, Decker LM, Dierks T. Effects of varying amounts of pronation on the mediolateral ground reaction forces during barefoot versus shod running. J Appl Biomech 2010; 26: 205-214.

16. Squadrone R, Gallozzi C. Biomechanical and physiological comparison of barefoot and two shod conditions in experienced barefoot runners. J Sports Med Phys Fitness 2009; 49: 6-13.

17. Zhang X, Paquette MR, Zhang S. A comparison of gait biomechanics of flip-flops, sandals, barefoot and shoes. J Foot Ankle Res 2013; 6: 45.

18. Liberati A, Altman D G, Tetzlaff J. The PRISMA statement for reporting systematic reviews and metaanalyses of studies that evaluate health care interventions: explanation and elaboration. PLoS Med 2009; 6: 1000100.

19. Rothschild C. Running barefoot or in minimalist shoes: evidence or conjecture? J Strength Cond Res 2012; 34.
20. Simon F, Grey M J, Nicola H. Barefoot vs. common footwear: A systematic review of the kinematic, kinetic and muscle activity differences during walking. Gait Posture 2015; 42: 230-239.

21. Hall JP, Barton C, Jones PR. The biomechanical differences between barefoot and shod distance running: a preliminary meta-analysis. Sports Med 2013; 43: 1335-1353.

22. Baltich J, Maurer C, Nigg BM. Increased vertical impact forces and altered running mechanics with softer midsole shoes. Plos One 2015; 10: 87.

23. Bishop M, Fiolkowski P, Conrad B, Brunt D, Horodyski M. Athletic footwear, leg stiffness, and running kinematics. J Athl Train 2006; 41: 387-392.

24. Ferris DP, Liang K, Farley CT. Runners adjust leg stiffness for their first step on a new running surface. J Biomech 1999; 32: 787-794.

25. Fong YA, Smith RM, Hiller CE. Impact attenuation properties of jazz shoes alter lower limb joint stiffness during jump landings. J Sci Med Sport 2017; 20.

26. De Wit B, De Clercq D, Aerts P. Biomechanical analysis of the stance phase during barefoot and shod running. J Biomech 2000; 33: 269-278.

27. Divert C, Baur H, Mornieux G, Mayer F, Belli A. Stiffness adaptations in shod running. $\mathrm{J}$ Appl Biomech 2005; 21: 311-321.

28. Divert C, Mornieux G, Freychat P, Baly L, Mayer F, Belli A. Barefoot-shod running differences: shoe or mass effect? Int J Sports Med 2008; 29: 512-518.

29. Sinclair J, Atkins S, Taylor PJ. The effects of barefoot and shod running on limb and joint stiffness characteristics in recreational runners. J Motor Behav 2016; 48: 79-85.

30. Nin DZ, Lam WK, Kong PW. Effect of body mass and midsole hardness on kinetic and perceptual variables during basketball landing manoeuvres. J Sports Sci 2015; 34: 756 .

\section{*Correspondence to}

\section{Hai-Bin YU}

Department of Sports Sciences,

University of Taipei

Taiwan

Yung-Shen TSAI

Graduate Institute of Sports Equipment Technology

University of Taipei

Taiwan 